\title{
Ensino dos Conteúdos sobre Relevo na Geografia Escolar: análise de uma coleção de livros didáticos dos anos finais do ensino fundamental
}

\author{
Teaching of the Contents of Relief on the School Geography: analysis of a collection \\ of textbooks of the final years of primary school
}

Enseñanza de los Contenidos del Relieve de la Geografía Escolar: análisis de una colección de libros de texto de los últimos años de escuela primaria

\author{
Larissa Anjos Santos ${ }^{1}$ \\ Edna Lindaura Luiz ${ }^{2}$
}

\begin{abstract}
RESUMO: O presente trabalho constitui-se em parte do trabalho de conclusão de curso intitulado Entre montanhas e planícies: análise do tema relevo nos anos finais do ensino fundamental, apresentado para o Curso de Licenciatura em Geografia da Universidade do Estado de Santa Catarina - UDESC. Neste artigo foi discutido o papel do ensino do relevo nas aulas de Geografia na educação básica, mais precisamente nos anos finais do ensino fundamental, através de análises em livros didáticos - referentes aos quatro anos escolares - da coleção Expedições Geográficas, aprovado pelo PNLD de 2017. Primeiramente realizou-se uma discussão teórica acerca do papel do ensino de relevo e do livro didático na educação geográfica e, consequentemente apontou-se algumas análises realizadas nos livros referentes a conceitos, discussões e mapas apresentados nas obras. Através dessas análises foi possível constatar que, mesmo o livro didático sendo um artefato significativo às diferentes escalas do sistema educacional brasileiro, os conteúdos presentes nele possuem pontos a serem discutidos e aprimorados. Esses apontamentos são realizados não com o intuito de desqualificar os livros, mas visando uma educação geográfica que integre as necessidades do mundo contemporâneo e dos estudantes.
\end{abstract}

PALAVRAS CHAVE: Livro didático. Geomorfologia escolar. Educação geográfica.

ABSTRACT: The present paper constitutes part of the final project entitled Between mountains and Plains: analysis of the theme in relief final years of elementary school, presented to the course in geography from the University of the State of Santa Catarina - UDESC. This article will be discussed the role of education in geography lessons in basic education, more precisely in the final years of

\footnotetext{
${ }^{1}$ Programa de Pós-Graduação em Educação FAED/UDESC, Av. Me. Benvenuta, 2007 - Itacorubi, Florianópolis - SC, 88035001, lariiianjos@gmail.com.

2 Departamento de Geografia da Universidade do Estado de Santa Catarina, Av. Me. Benvenuta, 2007 - Itacorubi, Florianópolis - SC, 88035-001, elinluiz@uol.com.br.
} 
primary school, through analysis in textbooks - relating to four school years - the collection Expedições Geográficas, approved by PNLD to 2017. First there was a theoretical discussion about the role of education and the textbook on geographical education and, consequently pointed out some analysis on the books regarding the concepts, arguments and maps presented in the works. Through these analyses, it was found that, even the textbook being a significant artifact of the different scales of Brazilian educational system, the contents present in it have points to be discussed and improved. These notes are held not in order to disqualify the books, but targeting a geographic education that can meet with the needs of the contemporary world and students.

KEYWORDS: Textbook. Teaching relief. Geographical education.

RESUMEN: El presente trabajo constituye parte del proyecto final titulado Entre montañas y llanuras: Análisis de relieve en los últimos años de la escuela de primaria, presentado al curso de licenciatura en Geografía de la Universidad de estado de Santa Catarina - UDESC. Neste artículo será discutido el papel de lo enseñanza de relieve en las lecciones de geografía en educación básica, más precisamente en los últimos años de escuela primaria, por la prueba de libros de texto - relativos a cuatro años de escuela - la colección Expedições Geográficas, aprobada por el PNLD hasta el 2017. Primero hubo una discusión teórica sobre el papel de de lo enseñanza de relieve y el libro de texto sobre la educación geográfica y, posteriormente señaló algunos análisis realizados en los libros relativos a conceptos, argumentos y mapas presentados en las obras. A través de estos análisis Se constató que, incluso el libro de texto es un artefacto importante de las escalas de diferentes sistemas educativos de Brasil, los contenidos presentes en él, tienen puntos para ser discutido y mejorado. Estas notas se llevan a cabo no para descalificar a los libros, pero dirigidas a una educación geográfica que puede satisfacer las necesidades de los estudiantes y el mundo contemporáneo.

PALABRAS CLAVE: Libro de texto. Enseñanza de relieve. Educación geográfica.

\section{INTRODUÇÃO}

O relevo se constitui no conjunto de formas morfológicas da superfície da Terra, incluindo também os processos modeladores destas, tanto derivados da dinâmica superficial quanto da dinâmica interna do planeta. Sendo assim, o estudo do relevo permeia conhecimentos relacionados à forma geral da Terra, às estruturas específicas da irregularidade da superfície terrestre - abrangendo relevo continental e oceânico - e seus processos modeladores, que atuam de forma direta e/ou indireta no estabelecimento das sociedades, representando o substrato físico onde se assentam as estruturas e ações humanas.

Em sociedades antigas que funcionavam basicamente com regime agrário, a sobrevivência dos sujeitos dependia dos ritmos e processos da natureza. Para tanto, o conhecimento do relevo e de seus processos modeladores tornava-se parte fundamental do cotidiano dessas pessoas e, sendo assim, era transmitido culturalmente através das gerações. Entretanto, no mundo contemporâneo, grande parte dos sujeitos, principalmente 
os que vivem em áreas urbanas, distanciou o seu cotidiano da vivência com os processos e fenômenos da natureza.

Contudo, mesmo tendo ciência do referido enfraquecimento das ligações entre os conhecimentos das dinâmicas naturais e o cotidiano do ser humano do século XXI, o relevo continua sendo utilizado pelas pessoas e estas continuam semelhantes a modelos anteriores, agindo sobre ele e sofrendo interferências de seus processos dinâmicos característicos. Dessa forma, o intuito desse trabalho é, através das análises de livros didáticos, questionar e analisar como o tema relevo vem sendo trabalhado nesse material.

A questão de o relevo ser um dos elementos organizadores do espaço geográfico possui potencial a ser estudado na educação básica, uma vez que esse conhecimento pode auxiliar as pessoas a compreenderem as dinâmicas em seus espaços de vivência, bem como os recortes espaciais mais amplos. Para além de compreender como se estruturam e organizam as morfologias de relevo em cada lugar, pensa-las e identifica-las para além de suas formas pode auxiliar os estudantes a compreenderem o espaço de maneira mais integral, estabelecendo relações entre diversos fatores da sociedade, como economia, qualidade de vida e urbanização, dentre outros e, por consequência, formando um pensamento geográfico.

Os conteúdos ministrados nas escolas públicas brasileiras, via de regra, possuem suporte teórico e a organização curricular anual pautada nos livros didáticos que, por sua vez, possuem sua elaboração seguindo diretrizes curriculares estabelecidas legalmente em documentos oficiais. Logo, esse material eminentemente escolar acaba possuindo um protagonismo nas instituições de ensino, tanto para professores, em seus planejamentos e aplicações das aulas, como para os estudantes, por ser - em alguns casos não tão raros - a única fonte de acesso e pesquisa aos conteúdos curriculares - e mais que isso, às imagens, mapas e outros artifícios visuais e didáticos fundamentais ao ensino de Geografia.

Tendo em vista a expressividade desse material à educação básica e compreendendo que os livros didáticos são materiais produzidos por meio de conjuntos de forças políticas e sociais, a escolha por realizar as análises não parte somente do pressuposto de indicar possíveis equívocos e potencialidades presente nesses, mas de realizar olhares particulares à área do ensino de Geografia - referente à temática de relevo, mais especificamente no que tange à Geomorfologia - que auxiliem nos debates atuais sobre os conteúdos da referida disciplina presentes nos livros, apresentando sugestões e apontamentos próprios da área com a finalidade de contribuir na elaboração de livros didáticos coerentes à ciência geográfica.

Diante da relação do relevo com as atividades humanas e a análise dos espaços e saberes geográficos, este artigo - oriundo do trabalho de conclusão de curso "Entre montanhas e planícies: análises do tema relevo nos anos finais do ensino fundamental" - 
pretende investigar como o tema é levantado e discutido em uma coleção de livros didáticos utilizada na disciplina de Geografia nos anos finais do ensino fundamental de uma escola pública da rede estadual de ensino de Santa Catarina.

A elaboração do presente trabalho partiu da intencionalidade de analisar os conteúdos de relevo em livros didáticos de ensino fundamental utilizados por uma escola da rede estadual de ensino de Santa Catarina. O olhar analítico aos quatro livros da coleção Expedições Geográficas se deu através de critérios de análise estabelecidos a partir de trabalhos realizados com perspectivas semelhantes e de questões singulares a esta pesquisa, sendo permeados pontos referentes a conceitos, textos, imagens e mapas que estivessem relacionado à temática em questão.

\section{OS CONHECIMENTOS PRÉVIOS E A GEORMOFOLOGIA NA CONSTRUÇÃO DE UM SABER GEOGRÁFICO}

Tendo em vista a influência do relevo na sociedade atual e na apropriação do espaço geográfico, partindo das diferentes realidades à que os sujeitos estão submetidos, na esfera econômica, social e habitacional, é pertinente pensar e questionar como o tema está sendo abordado na esfera educacional brasileira, tanto na escala econômica e política, por meio das leis e políticas públicas direcionadas à educação básica e a formação de professores, como no cotidiano escolar, nas salas de aula, observando os conteúdos e materiais didáticos utilizados no ensino da ciência geográfica.

No âmbito do ensino fundamental, ao ser abordado nas aulas de Geografia, o relevo não deveria ser subentendido como um tema ensinado através de conceitos e expressões memorizáveis e nem de conteúdos que possuam discussões abstratas e complexas, como muitas vezes é demonstrado em livros e outros materiais didáticos. Este possui, mesmo que não cultural e historicamente, potencial de incentivar os estudantes a pensar a sociedade de maneira integradora quanto aos seus elementos e agentes, pois a partir do entendimento dos aspectos do relevo é possível compreender questões econômicas e sociais presentes na sociedade moderna, como, por exemplo, a ocupação de áreas de risco, o desenvolvimento de atividades turísticas em certos locais e a estrutura agrária e fundiária, entre outras.

Nessa perspectiva os conteúdos da Geografia Física, em alguns casos, perdem espaço em discussões sociais e políticas comparativamente a outros temas inseridos nas aulas de Geografia na educação básica, como a Geografia Econômica e a Geopolítica, por exemplo. Contudo, Bertolini (2010) alerta que, mesmo no contexto onde os tópicos relacionados aos elementos físicos do espaço parecem desaparecer dos currículos escolares - atualmente tal apontamento encontra-se em voga com a sanção da Base 
Nacional Comum Curricular - é importante salientar que, se a episteme da Geografia é estabelecer relações entre o meio físico natural, os seres humanos e a sociedade, não é possível pensar um fazer geográfico atentando-se a somente um desses fatores isoladamente.

O primeiro contato com o conteúdo de relevo em sua especificidade e, portanto, a operacionalização de conceitos e processos relacionados a este, transcorre, de maneira geral, no sexto ano do ensino fundamental. Contudo, Ascenção, Ferreira e Valadão (2016) apontam que, nesse momento, os materiais didáticos em sua maioria e os conteúdos programáticos, priorizam abordagens macroescalar, ou seja, que representam e explicam estruturas e fenômenos relacionados ao tempo geológico, não contribuindo para o relevo como um componente dinâmico do cotidiano.

Tendo em vista que a educação brasileira segue a herança comeniana de educação onde os conteúdos são elaborados e ensinados de maneira seriada, em níveis de complexidade de acordo com o passar dos anos escolares - é possível inferir, sustentandose na ideia de Ascenção (2009), que no sexto ano o relevo teria que ser abordado a partir das mesoformas, tendo em vista que estas são estruturas visíveis na paisagem e que auxiliam na compreensão do significado social que o relevo possui. Os conceitos macroescalares mais complexos, como o relevo brasileiro e mundial, as depressões e os dobramentos modernos, por exemplo, também precisam ser discutidos e ensinados, contudo podem ser trabalhados de maneira mais intensa no primeiro ano do ensino médio, no qual os conteúdos geográficos retomam a temática. Nessa etapa escolar os estudantes já possuem nível de abstração maior, podendo compreender temáticas mais complexas e globais.

Para ensinar Geomorfologia, portanto, é necessário esclarecer as categorias e conceitos que a amparam, tais como: escala espacial, escala temporal, processos, agentes, formas e etc. (BERTOLINI, 2010). Sendo assim, ao estudar o relevo nas aulas de Geografia, essas categorias precisam ser abordadas e diferenciadas de maneira compreensível. Ao relacionar a escala do tempo presente - histórico - com o relevo local, os estudantes podem compreender a realidade e as mudanças do ambiente em que vivem, pois a percepção da ação agente exógena - morfoclimáticos -, por parte destes, pode auxiliar na compreensão dos fenômenos que ocorrem nas formas de relevo existentes em seus locais de vivência, potencializando, assim, a maneira com que os estudantes irão lidar com as possíveis transformações, efêmeras ou gradativas, ao qual o relevo está submetido.

Contextualizando as dinâmicas da natureza através das categorias de análise da Geomorfologia, como as escalas espaciais e temporais, por exemplo, consegue-se conceber que o ser humano, como um ser social, encontra-se inserido nas formas básicas de relevo e, em muitos casos, mesmo sem perceber, atua sobre elas (nesse trabalho adota- 
se a diferenciação conceitual das estruturas de relevo entre FORMA e COMPARTIMENTO. Segundo Ab'Saber (1975) compartimento de relevo é um conjunto topográfico de determinada região e as formas são estruturas básicas que, segundo o mesmo autor, se configuram como partes de um todo e/ou elementos isolados em alguns conjuntos, que se encontram situadas no interior dos compartimentos). Ao adquirir um lote urbano, escolhendo àquele situado em áreas aplainadas ao invés de outros localizados em áreas com relevo mais acidentado; na construção de estradas e rodovias ou no uso de determinado solo e relevo para atividades agrícolas, percebe-se que o relevo está sendo utilizado a todo momento. Todavia, além disso, é necessário compreender que a maneira como se utiliza e o acesso que se tem às formas de relevo não é análogo a todos, as condições são desiguais e refletem quem detém o poder social e como o modelo econômico adotado por uma sociedade pode ser espelhado em sua estrutura física, disposta pelas diferentes formas e compartimentos de relevo. Para que os estudantes compreendam as temáticas de relevo e a partir delas possam refletir de maneira geográfica, estabelecer relações entre o conhecimento científico com o conhecimento cotidiano é fundamental. Para tanto e alicerçada em Cavalcanti (2006), é possível afirmar que é do confronto da dimensão do vivido, isto é, da realidade vivenciada pelos estudantes cotidianamente, com o concebido socialmente - os conceitos científicos - que é possível estabelecer a possibilidade de uma melhor compreensão do vivido, pela internalização consciente do concebido. Ou seja, é a partir da relação entre o conhecimento científico em interface com as vivências e experiências do cotidiano que os estudantes compreenderão o conteúdo de forma acadêmica a fim de aplica-lo, de maneira atuante e consciente, na sociedade em que vivem.

A Geomorfologia é habitualmente denominada como uma área complexa do estudo geográfico. Isso se dá por essa área de conhecimento oferecer uma diversificada e difícil terminologia técnica, apresentando um grau de dificuldade maior na construção de conhecimento por parte dos estudantes (PEREIRA; SILVA, 2012). Além disso, Carvalho (1999), em pesquisas baseadas em Debesse-Arviset, aponta que na educação básica os estudantes apresentam dificuldades na compreensão da conceituação da terminologia, visto que para esses o termo relevo caracteriza-se somente pelas partes do terreno que possuem elevação. Sendo assim, ao estabelecer relações que aliem as dimensões científica e empírica, o conhecimento pode ser mais facilmente ampliado, tornando informações que antes eram desconexas em produções de conhecimento científico sistematizado.

\section{O LIVRO DIDÁTICO E OS CONTEÚDOS DE RELEVO}

A necessidade de estabelecer parâmetros curriculares comuns que pudessem orientar objetivos, habilidades, competências e conteúdos a serem ministrados nas instituições 
escolares e que auxiliassem na elaboração de materiais didáticos a nível nacional, vem sendo pauta de discussões e propostas no cenário político brasileiro, mais significativamente desde o início da década de1990. Nessa época, foram promulgadas a Lei de Diretrizes e Bases da Educação Brasileira - Lei n 9394/96 -, os Parâmetros Curriculares Nacionais - PCN's -, e foi criado o Programa Nacional do Livro Didático - PNLD. Mais recentemente, nos anos 2000, foram homologadas também as Diretrizes Curriculares Nacionais - DCN's - e o Plano Nacional de Educação - Lei n 13.005 - que, como forma de ceder à pressão exterior sobre os resultados nos índices educacionais brasileiros, determina 20 metas e estratégias para tal segmento a serem cumpridas num período de 10 anos. Ainda nessa década - no ano de 2015 - iniciou-se a discussão acerca da construção de uma Base Nacional Comum Curricular para todas as instituições, públicas ou privadas, de educação básica (BRASIL, 2016).

Todas as políticas educacionais supracitadas exercem influência na elaboração dos materiais didáticos disponibilizados pelo governo aos estudantes brasileiros, ora por elencar e/ou definir conteúdos mínimos e temáticas basilares a serem discutidas nos livros, ora por analisar e avaliar esses materiais para, caso estejam de acordo com as diretrizes que the são cabíveis, serem distribuídos nas escolas. Com a criação da BNCC, os livros didáticos passarão a ter sua elaboração direcionada por esse documento, não considerando mais os PCN's como norteadores de conteúdo. Contudo, já contextualizado que, por esse artigo ser oriundo de uma pesquisa realizada no ano de 2017 , os livros didáticos que foram analisados e que serão discutidos posteriormente tiveram sua construção seguindo diretrizes pautadas nos PCN's, pois os primeiros materiais a serem distribuídos conforme as novas normativas, serão os aprovados pelo PNLD de 2020.

Os livros didáticos estão presentes cotidianamente em muitas salas de aula em diferentes lugares do mundo, sendo considerado um artefato propriamente escolar e que possui - mesmo com todos os debates que se inserem referente a sua utilização, estruturação e mercantilização - grande importância para estudantes e professores. Firmino e Martins (2017) reforçam essa concepção quando apontam para além de uma discussão binária sobre o livro didático ser ou não um bom aliado na educação brasileira. Estes resistem verticalmente através de programas governamentais e estão longe de ser obsoletos, sendo o principal recurso para educandos e educadores nas aulas de Geografia, História, Matemática e outras.

Esses materiais didáticos, por mais importantes e necessários que sejam para a educação brasileira, não possuem neutralidade em suas páginas. Tonini (2003, p. 36) aponta que estes, mesmo sendo um artefato iminentemente escolar, são considerados "[...] como um campo do saber, moldado pelas relações de poder que o constituem". Sendo assim, a maneira como os conteúdos estão dispostos nos livros e a forma como estes são 
escritos e contextualizados trazem consigo ideologias e discursos que, mesmo sutis, indicam tais relações de poder. Os conteúdos de relevo, como tantos outros da ciência geográfica, carregam, em seus textos, imagens e mapas com esse caráter.

Tendo em vista conteúdos e discursos propagados com e nos livros didáticos, Costella (2017) em seu texto "Nas entrelinhas do Livro Didático: a voz e a visibilidade do aluno" aponta uma discussão acerca das possibilidades de se fazer Geografia através das entrelinhas existentes nesse material. Segundo ela, o professor na sua prática diária e nas reflexões entre conteúdo e realidade busca os saberes geográficos nas entrelinhas dos livros didáticos, pois, segundo a autora "[...] não há como o professor trabalhar com seus alunos, de forma a desenvolver potencialidades e reflexões, se obedecer a lógica separatista dos assuntos didaticamente colocado nos manuais" (COSTELLA, 2017, p. 179). Nessa perspectiva, e retomando o que já foi discutido anteriormente, percebe-se que são nas entrelinhas dos conteúdos descritos nos livros didáticos e nas relações com os conhecimentos prévios dos estudantes e das realidades vivenciadas por estes que a educação geográfica encontrará o potencial de desenvolver reflexões e potencialidades enquanto ciência do espaço e da sociedade.

Tendo tais perspectivas teóricas como base para guiar um olhar analítico aos livros didáticos, serão levantadas a seguir algumas das análises realizadas em livros de sexto ao nono ano da coleção "Expedições Geográficas" - referente ao PNLD de 2017. Para poder realizar tal investigação foram elencados - no trabalho que origina o presente artigo - oito critérios de análises com base em pesquisas de Pontuschka, Paganelli e Cacete (2009) e Albano (2016). A apresentação e descrição da coleção; as capas; a apresentação do índice e a organização da temática; os conceitos e discussões apresentados; a relação dos conteúdos com a realidade; a utilização de imagens e representações cartográficas; as atividades e outras considerações foram os oito critérios elencados para a análise dos livros. Todavia, para o momento - devido ao limitado número de caracteres - serão levantados e discutidos apenas alguns dos pontos que foram utilizados na investigação inicial - os grifados acima.

Primeiro optou-se por situar o leitor - de acordo com observações prévias realizadas nos livros didáticos e nos documentos oficiais que os direcionam - quais são as principais temáticas abordadas em cada ano escolar, para poder compreende então como se atribui presença e a maneira com que o relevo é contextualizado nesses materiais. O sexto ano é caracterizado por possuir introduções acerca da disciplina de Geografia, para isso trabalha principalmente com a questão cartográfica e com os temas relacionados à formação do globo terrestre e suas dinâmicas naturais e sociais. No sétimo, o olhar se torna mais preciso, centrado integralmente nos aspectos geográficos do território brasileiro. No oitavo ano, amplia-se consideravelmente o olhar, abordando temáticas físicas, sociais e econômicas 
referentes às Américas. No nono, por fim, apresenta-se uma visão global, desenvolvendo discussões referentes aos continentes ainda não mencionados, à geopolítica global e outras temáticas.

Ao analisar os livros da coleção, foram identificados, em todos os anos escolares, equívocos conceituais no que tange à definição de alguns termos próprios aos conteúdos de relevo. Contudo, o objetivo central desse artigo não é apenas indicar esses equívocos, mas problematizar as conceituações como centro da educação geográfica.

Dessa forma, no sexto ano, os autores definem planalto como "[...] áreas da superfície terrestre menos elevadas que as montanhas e mais ou menos planas, delimitadas por escarpas" (ADAS; ADAS, 2015a, p. 107). Tendo ciência da definição de planalto, salienta-se que, dentre outros equívocos na conceituação apresentada, esta morfologia não pode ser definida como uma superfície mais ou menos plana, pois os planaltos são caracterizados como grandes áreas de relevo que podem ou não possuir diversas formas em sua dimensão, como morros, vales e até montanhas. Mas como a definição dada pelos autores pode influenciar na compreensão dos estudantes sobre o relevo partindo das relações cotidianas destes? Um estudante que reside na cidade de Urubici, no estado de Santa Catarina, ou em Belo Horizonte, por exemplo, convive diariamente com morros e outras elevações circundando a cidade e, sendo estas localizadas em regiões planálticas, não possuem os traços "planos" que é exemplificado no texto. Além de causar uma confusão conceitual nos sujeitos, estes podem acabar não estabelecendo relações entre as características da cidade onde vivem e a definição que thes foi concedida, podendo gerar imprecisão no reconhecimento das dinâmicas do lugar onde moram.

Ainda no sexto ano, os autores levantam a discussão sobre a ação dos ventos, das geleiras e dos seres vivos no relevo. Nesse momento conceituam o termo "Reg", que são geomorfologicamente falando - pavimentos detríticos localizados em desertos, tendo sua formação constituída através do intemperismo físico nas rochas. Considerando que Reg é uma forma específica de relevo não encontrada no Brasil e que, no sexto ano, os estudantes estão iniciando as discussões geográficas, entende-se que tal conceituação não se torna essencial para a construção de um conhecimento geográfico nesse período, aliás, tal formação morfológica não possui relação direta com a realidade dos estudantes brasileiros. Partindo desse pressuposto, ainda no mesmo livro, os autores conceituam as dunas como formas de relevo construídas através da ação do vento, contudo, para exemplificar, a imagem que utilizam é de um tipo específico de dunas, chamado de barcanas, que, como os Reg's, só existem em zonas desérticas. Logo, seria conveniente incluir outros tipos de dunas comuns no litoral brasileiro, como as parabólicas, transversais ou longitudinais, que fazem parte do cotidiano de estudantes que moram em áreas litorâneas. 
No sétimo ano são abordados os Domínios Morfoclimáticos, classificação esta que, em diversos continentes, é utilizada como a materialização das influências diretas e indiretas exercidas pelas condições climáticas atuais e pretéritas sobre a morfogênese do relevo terrestre (JATOBÁ, 2001, p. 34). No Brasil, esses domínios foram estabelecidos e organizados pelo geógrafo Aziz Ab'Saber, que através da conjugação de diversos fatores, como cobertura vegetal, clima, relevo e formações superficiais (solos), determinou unidades paisagísticas específicas e singulares do país.

Na concepção teórica do presente trabalho, compreende-se que esta é a forma mais adequada para ensinar, nas escolas básicas, sobre o relevo e as características que o compõem, pois os fenômenos que ocorrem na superfície terrestre não operam de forma isolada e cada um dos agentes - clima, relevo, vegetação e o próprio ser humano - atua de forma específica e concomitantemente relacionada no espaço-tempo para definir as características particulares de cada ambiente. Para exemplificar o supracitado, o livro do sétimo ano caracteriza os domínios da seguinte maneira:

Domínios florestados - formados por florestas naturais: o Domínio Amazônico, o Domínio dos Mares e Morros Florestados (Mata Atlântica) e o Domínio das Araucárias;

Domínios das formações vegetais naturais herbáceas e arbustivas Domínio dos Cerrados, Domínio da Caatinga e Domínio das Pradarias (Campos) [...] (ADAS; ADAS, 2015b, p. 33).

A setorização realizada pelos autores não evidencia a totalidade da classificação construída por Ab'Saber, pois destacam somente os elementos relacionados à vegetação e não a interrelação entre os agentes, que foi uma das premissas que caracterizavam essa forma de regionalização. De maneira geral, nos quatro livros analisados, encontra-se a presença de diversas imagens e mapas para ilustrar os conteúdos presente nos textos. Destaca-se mais adiante dois casos particulares de mapas que são reproduzidos diversas vezes para exemplificar os relevos de determinadas regiões - sejam estas no Brasil ou em outros lugares e/ou países do mundo.

Ao discutir sobre o tema relevo no decorrer dos capítulos, os livros geralmente apresentam um mapa físico (figura 1) como forma de ilustrar tal elemento. Contudo, cabe aqui uma reflexão, não direcionada somente aos livros didáticos, mas a todo o discurso que é produzido e propagado durante anos na Geografia escolar e acadêmica que, ao definir o mapa físico como aquele que representa o relevo, concebe uma redução desse elemento à um de seus fatores, a altimetria, não considerando a totalidade de agentes responsáveis por construir e modelar o relevo. Além disso, a titulação dessas representações como "mapa físico", aponta um reducionismo no que é apresentado, pois, como argumenta Santos (2017), o mapa físico possui como ponto de análise a altitude, mas esta é somente um dos 
fatores, ao lado de clima, relevo, geologia e outros, que compreendem o meio físico da Terra. Tais denominações, por não possuirem uma unanimidade conceitual, acabam gerando confusões em diferentes escalas da educação geográfica, tendo em vista que, no nono ano, ao representar o relevo de dois locais diferentes - Japão e Ásia - os autores utilizam mapas que representam o mesmo elemento, mas que possuem diferentes titulações, como é possível observar na figura 2.

\section{Figura 1 - Mapa Mundi "físico"}

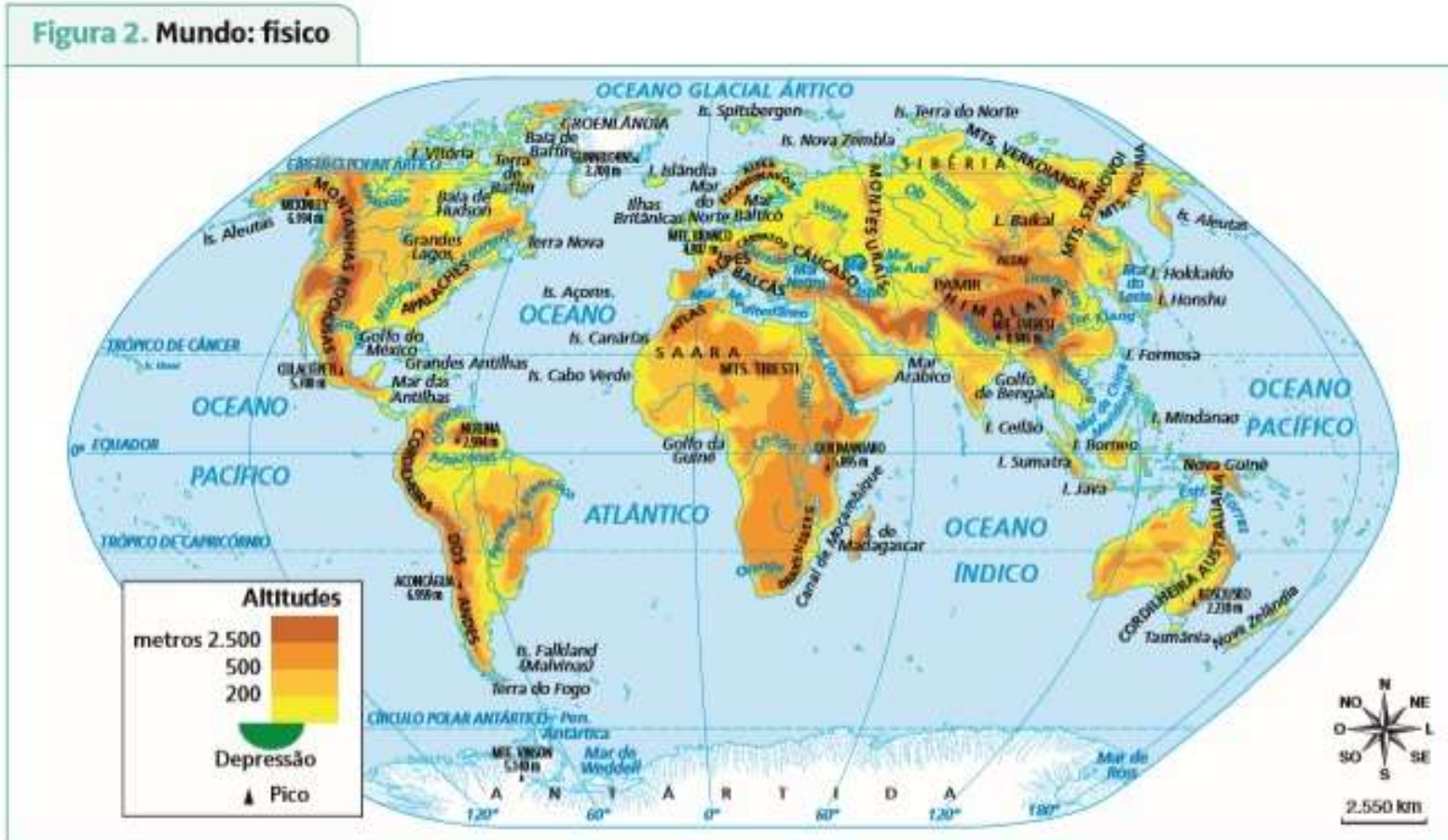

Fonte: FERREIRA, Graça M. L. Atlas geográfico: espaço mundial. 4. ed. Säo Paulo: Moderna, 2013.p. 20.

Fonte: Adas e Adas (2015a).

Retomando a discussão realizada na primeira análise, reforça-se também que ao apresentar um mapa com um nível alto de generalização para estudantes de sexto ano, torna-se possível que estes não compreendam como tais estruturas interferem em suas realidades, deslocando assim o olhar que deveria ser do próximo - da realidade vivenciada cotidianamente - para algo abstrato. Ao discutir sobre o relevo brasileiro, principalmente em livros de sexto e sétimo ano, os autores utilizam o mapa elaborado por Jurandir Ross (figura 3) para exemplificar e ilustrar tal classificação. Contudo, para a compreensão deste, é necessário um conhecimento técnico nas áreas de geomorfologia e geologia, conhecimento este que estudantes do ensino fundamental ainda estão desenvolvendo. 
Figura 2 - Mapas que representam a altimetria com titulações diferentes: "Japão: relevo e placas tectônicas" e "Ásia: físico"
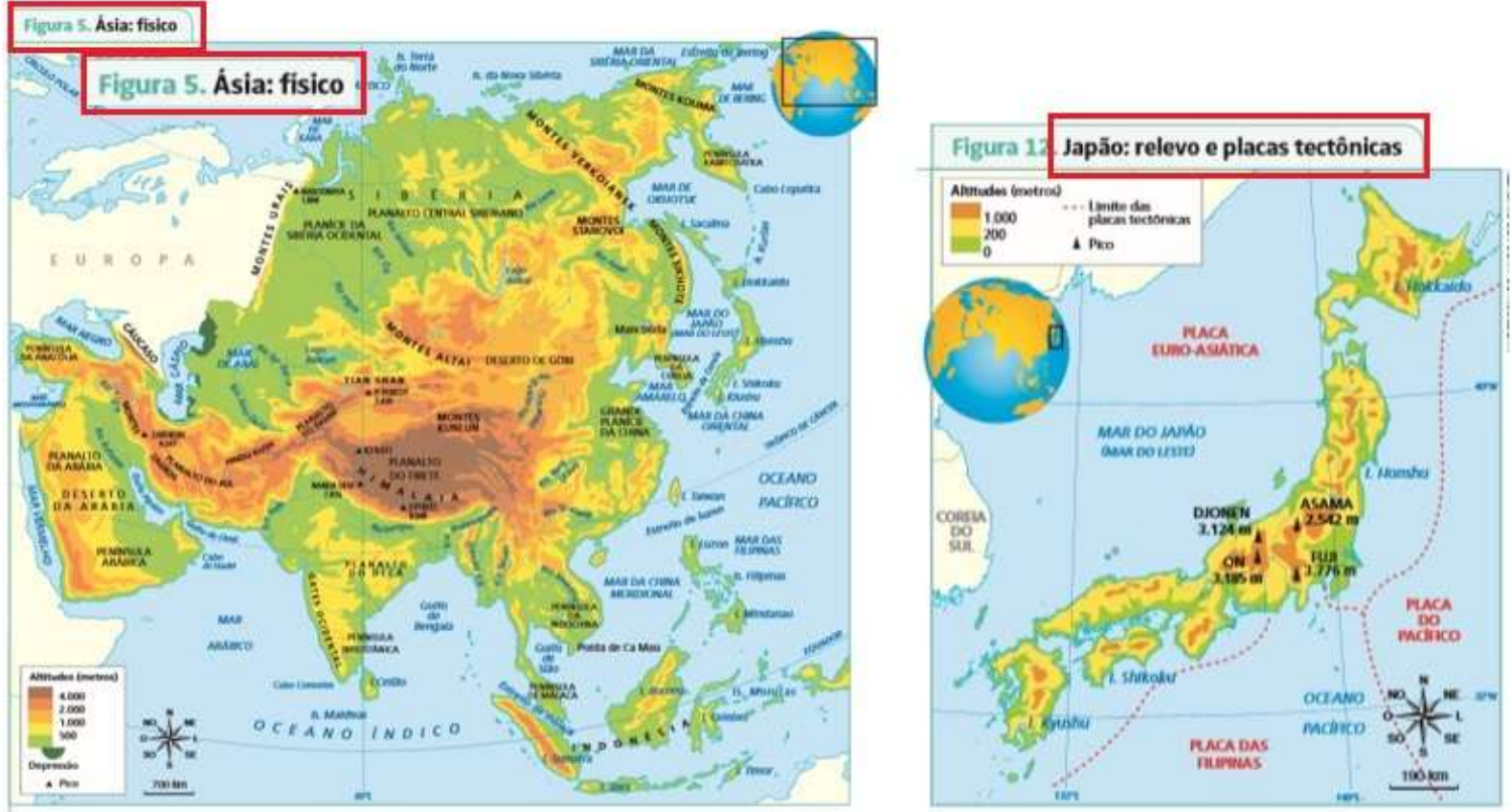

Fonte: Adas e Adas (2015c).

Figura 3 - Mapa da regionalização do relevo

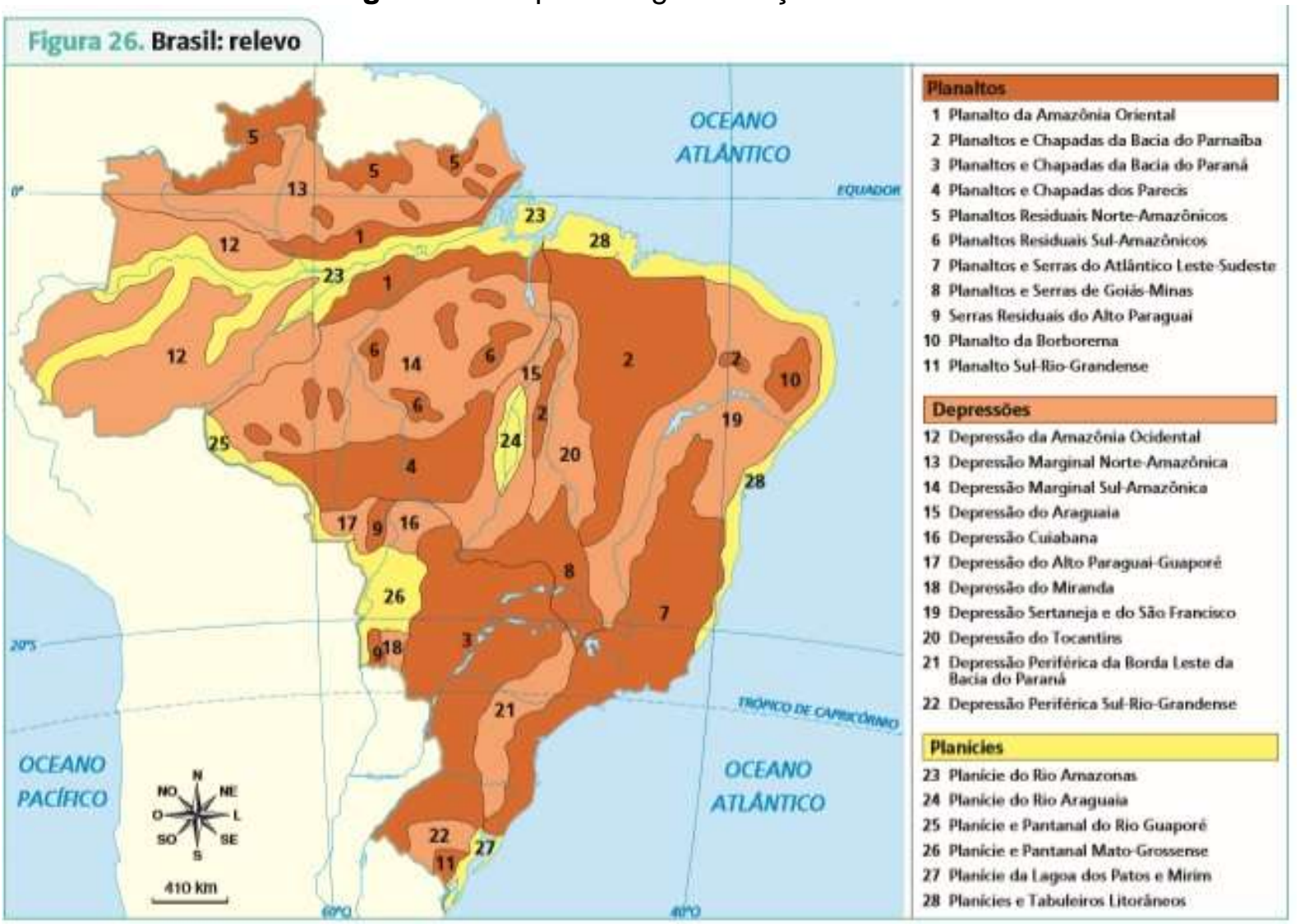

Fonte: Adas e Adas (2015a). 
Por fim, em relação às representações cartográficas, destaca-se uma em particular no livro do nono ano que retrata a representação dos aspectos fisiográficos da China definição semelhante aos domínios morfoclimáticos de Ab'saber. Nesse mapa encontram-se informações referentes aos cursos d'água, das precipitações, do relevo, das vegetações e do clima, como pode ser observado na imagem da figura 4. Partindo do supradito, os Parâmetros Curriculares Nacionais revelam a importância da relação desses componentes como uma forma de compreender a dinâmica da natureza ao defender que:

É fundamental tratar os componentes da natureza nas suas especificidades, mas sem perder de vista que muitos dos seus mecanismos são interativos. Por exemplo, é fundamental relacionar o clima e a vegetação, os solos e o relevo, ou ainda como clima, solos e relevo se interrelacionam (BRASIL, 1998, p. 62).

Figura 4 - Mapa fisiográfico da China

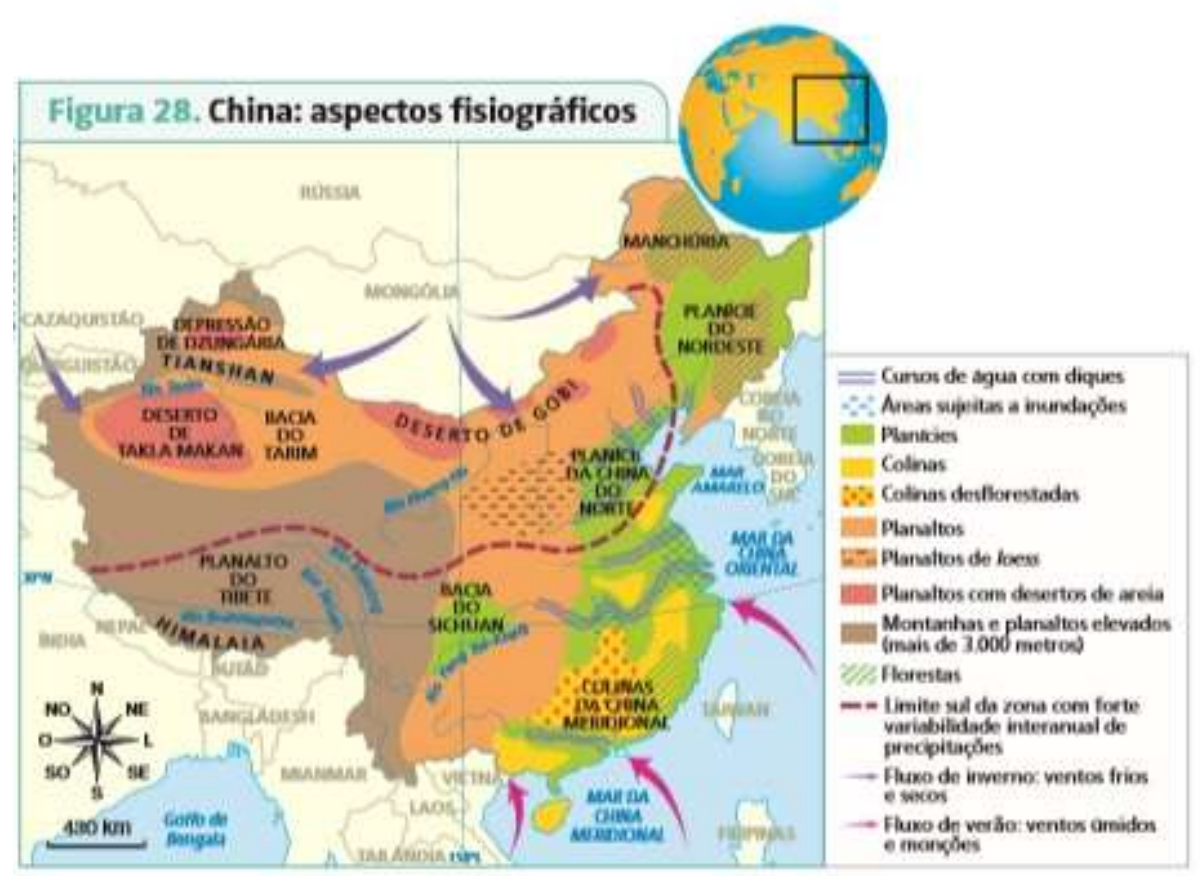

Fonte: Adas e Adas (2015d).

Sendo assim, entende-se que a forma conjunta como foi representada esses fatores num mapa auxilia, mesmo que o estudante não conheça o local, a compreender como ocorre a dinâmica geral do país em relação aos aspectos físico-naturais e, partindo desse pressuposto, defende-se aqui que esse tipo de representação pode ser empreendido nos livros didáticos como forma de auxiliar nessa compreensão.

As análises realizadas apresentam apontamentos próprios de uma pesquisa com enfoque em determinado tema e, portanto, discute singularidades referentes aos conteúdos de relevo num âmbito mais específico de estudo. Essa especificidade no olhar auxilia na possível percepção de conteúdos e discursos que reforçam estereótipos que, por vezes, 
poderiam não ser notados através de um olhar abrangente. A titulação de um mapa como o caso apontado pode, mesmo sendo um detalhe, gerar uma sucessão de fatos que reforcem uma ideia imprecisa em relação aos conteúdos da disciplina e a percepção dos estudantes perante os temas que são ensinados. Sendo assim, não significa ater-se aos pormenores da ciência geomorfológica, mas sim de preocupar-se com casos específicos desta que podem influenciar o todo do saber geográfico.

\section{CONSIDERAÇÕES FINAIS}

Considera-se que o conteúdo de relevo nas aulas de geografia, como apresentado aqui, deve superar as classificações morfológicas da paisagem, como as planícies, montanhas e os vales, por exemplo. O escopo de ensinar o relevo na educação básica, assim como o de ensinar as demais temáticas das diferentes disciplinas, é estabelecer relações e conexões entre conteúdos científicos e os conhecimentos cotidianos, empregando uma linguagem próxima aos estudantes. Para tanto, deve-se fugir da naturalização de que ao aprender os nomes e as características das formas de relevo os sujeitos compreendem o funcionamento destas, um dos propósitos desse trabalho, partindo da ideia de que, para compreender o relevo - principalmente no ensino fundamental - é preciso estabelecer relações entre as próprias formas morfológicas, suas dinâmicas e a maneira como estas atuam nos locais de vivências dos estudantes. Logo, ao compreender as possíveis relações entre o referido tema e as vivências dos estudantes - o eu, a minha casa e o meu bairro - a percepção deste para com o espaço pode ser deslocada, fazendo com que a conexão entre ser humano e natureza se estabeleça de maneira diferente do que antes era pensando e vivenciado.

Através das análises dos livros didáticos, identificou-se que há confusões conceituais e teóricas em algumas temáticas próprias ao relevo, como a definição de planalto, por exemplo. Contudo, há questões que englobam tal temática, mas que compreendem e influenciam também outros saberes e campos da ciência geográfica, como o caso das titulações dos mapas. Ambas as discussões - e outras, em diferentes áreas da Geografia quando não articuladas, continuam sendo impressas nos livros e reforçando estereótipos que, com o passar do tempo, acabam por ser naturalizados. Diante disso, entende-se que um olhar analítico sobre conteúdos e temáticas mais específicas se faz importante pois, através destes, podem surgir questionamentos e apontamentos que, em alguns casos, não são perceptíveis, tendo em vista que um pesquisador - ou o próprio professor - não consegue aprofundar todos os temas que abrangem a Geografia.

Mesmo abordando algumas discussões acerca de equívocos presentes nos livros didáticos analisados, não se discute aqui o binarismo desse material, classificando-os como 
bons ou não, necessários ou desnecessários à educação. Entende-se, portanto, que os livros são uma política pública e que estão presentes em praticamente todas as escolas da rede pública de ensino do país, logo as análises realizadas nestes não possuem o caráter de julgamento ou aprovação de um material que já é consolidado na realidade educacional brasileira, mas de críticas construtivas que fomentem debates para buscar o aprimoramento não só dos livros didáticos como reprodutores de conteúdos, textos e imagens, mas da educação geográfica como um todo.

\section{REFERÊNCIAS}

AB'SABER, A. N. Formas de relevo: texto básico. São Paulo: Edart, 1975.

ADAS, M., ADAS S. Expedições geográficas $6^{\circ}$ ano. São Paulo: Moderna, $2015 a$.

; __ Expedições geográficas $8^{\circ}$ ano. São Paulo: Moderna, 2015c.

; __ Expedições geográficas $9^{\circ}$ ano. São Paulo: Moderna, 2015d

ALBANO, A. Os conceitos de cidade e urbano no ensino de geografia: uma investigação em livros didáticos. 2016. Trabalho de Conclusão de Curso (Graduação em Geografia) Curso de Geografia, Universidade do Estado de Santa Catarina, Florianópolis, 2016.

ASCENÇÃO, V. O. R. Os conhecimentos docentes e a abordagem do relevo e suas dinâmicas nos anos finais do ensino fundamental. 2009. Tese (Doutorado em Geografia). Belo Horizonte. 2009. Disponível em:

http://www.bibliotecadigital.ufmg.br/dspace/bitstream/handle/1843/MPBB-

7Y5MBJ/valeria_tesefinal_completa.pdf;jsessionid=A0B2243B13390964B9156358

D096BD08? sequence $=1$. Acesso em: 20 out. 2018.

.; FERREIRA, L. R.; VALADAO, R. C. O estudo do relevo e interpretações do vivido no 6a ano do ensino fundamental. In: FÓRUM NEPEG: A GEOGRAFIA NO CENÁRIO DAS POLÍTICAS PÚBLICAS EDUCACIONAIS CONTEMPORÂNEAS, 7., 2016, Caldas Novas. Anais [...]. Goiânia: UFG, 2016. v. 1, p. 459-464.

BERTOLINI, W. Z. O ensino de relevo: noções e propostas para uma didática da geomorfologia. 2010. Dissertação (Mestrado em Geografia e Análise Ambiental). Minas Gerais. 2010. Disponível em:

file:///C:/Users/f6lan/Downloads/disserta_o_completa\%20(3).pdf. Acesso em: 1 nov. 2018.

BRASIL. Ministério da Educação. Secretaria da Educação Básica. Base nacional comum curricular. Brasília, DF, 2016. Disponível em:

<http://basenacionalcomum.mec.gov.br/\#/site/inicio>. Acesso em: 15 jan. 2019.

Secretaria de Educação Fundamental. Parâmetros Curriculares Nacionais: Geografia. Brasília: MEC/ SEF, 1998.

CARVALHO, A. L. P. Geomorfologia e geografia escolar: o ciclo geográfico davisiano nos manuais de metodologia do ensino (1925-1993). 1999. Dissertação (Mestrado em Geografia). Florianópolis. 1999.

CAVALCANTI, L. S. Geografia, escola e construção do conhecimento. Campinas: Papirus, 2006.

COSTELLA, R. Z. Nas entrelinhas do Livro Didático: a voz e a visibilidade do aluno. In: TONINI, I. M. et al. O livro didático de Geografia e os desafios da docência para aprendizagem. Porto Alegre: Sulina, 2017. p. 177-190. 
FIRMINO, L. C.; MARTINS, R. E. M. W. Imagens-clichês e Livros Didáticos: reflexões para o ensino de Geografia. In: TONINI, I. M. et al. O livro didático de Geografia e os desafios da docência para aprendizagem. Porto Alegre: Sulina, 2017. p. $103-112$.

JATOBÁ. L. O ensino do tema Domínios morfoclimáticos do Brasil. Revista do Instituto Brasileiro de Edições Pedagógicas: Área de conhecimento - Geografia, [S.I.] Ano 1, p. 64-40, nov. 2001.

PEREIRA, J. S.; SILVA, R. G. S. O ensino de geomorfologia na educação básica a partir do cotidiano do aluno e o uso de ferramentas digitais como recuso didático. Revista de ensino de Geografia, Uberlândia, v. 3, n. 4, p. 69-79, jan./jun. 2012. Disponível em:

<http://www.revistaensinogeografia.ig.ufu.br/N.4/art5v3n4.pdf>. Acesso em: 25 out. 2018.

PONTUSCHKA, N. N.; PAGANELLI, T. I.; CACETE; N. H. Para ensinar e aprender Geografia. São Paulo: Cortez, 2009.

SANTOS, L. A. Entre montanhas e planícies: análise do tema relevo nos anos finais do ensino fundamental. 2017. Trabalho de Conclusão de Curso (Graduação em Geografia) Curso de Geografia, Universidade do Estado de Santa Catarina, Florianópolis, 2017.

TONINI, I. M. Imagens nos livros didáticos de Geografia: seus ensinamentos, sua pedagogia. Mercator, ano 2, n. 4, p. 35-44, 2003.

Recebido: dezembro de 2018. Aceito: março de 2019. 